\title{
REGIONALISMO E COMUNIDADE IMAGINADA NA OBRA DA RORAIMENSE NENÊ MACAGGI
}

\section{REGIONALISM AND COMMUNITY IMAGINATED IN THE WORK OF RORAIMENSE NENE MACAGGI}

\author{
Danielle dos Santos Pereira Lima ${ }^{1}$ \\ Rosidelma Pereira Fraga²
}

RESUMO: Este artigo é um produto final do projeto de iniciação científica $\mathrm{O}$ contador de histórias e o leitor de poesias, realizado na Universidade Estadual de Roraima, transformado em uma pesquisa de conclusão de curso. De modo embrionário, a pesquisa centrou-se no exame do regionalismo e da identidade cultural na poética de Nenê Macaggi. Como corpus de análise, o trabalho partiu de quatros romances publicados sobre a ponta norte do Brasil: A mulher do garimpo: romance do extremo sertão do Amazonas (1974); Dadá Gemada doçura e amargura: romance do fazendeiro roraimense (1980); Exaltação ao verde: terra, água e pesca (1984), Nará-Sué-Uarená (2012). A intenção é compreender a construção da identidade cultural em Macaggi, desvelando as estratégias simbólicas utilizadas pela autora na construção de um imaginário local, através de romances híbridos, que mais parecem relatos etnográficos. Todavia, trazem contribuições para o estudioso de Literatura, História e Antropologia e outros pesquisadores, ao retratar a construção poética, histórica e cultural do Estado de Roraima. As discussões elencadas nesse artigo ancoram-se em autores como Stuart Hall (2004), José Luís Jobim (2012) e na obra do sociólogo Antonio Candido (1964).

Palavras-chave: Identidade; Regionalismo; Nenê Macaggi.
ABSTRACT: This paper is a final product of the research project The storyteller and poetry reader, held at the State University of Roraima, transformed into a course completion research. Embryonic, the research focused on the examination of regionalism and cultural identity in the poetics of Nene Macaggi. As analysis corpus, the work came from four novels published on the northern tip of Brazil: Woman panning: romance extreme hinterlands of the Amazon (1974); Dada Eggnog sweetness and bitterness: Romance roraimense Farmer (1980); Exaltation of the green earth, Water and fishing (1984), Nara-Suê-Uarená (2012). The intention is to understand the construction of cultural identity in Macaggi, revealing the symbolic strategies used by the author in the construction of an imaginary place, through hybrid novels that look more like ethnographic accounts. However, they bring contributions to the literature scholar, History and Anthropology and other researchers, to portray the poetic, historical and cultural construction of the State of Roraima. Discussions listed in this article anchor in authors such as Stuart Hall (2004), José Luis Jobim (2012) and the work of sociologist Antonio Candido (1964).

Keywords: Identity; regionalism; Nene Macaggi.

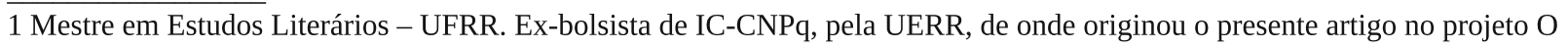
contador de histórias e o leitor de poesias.

2 Profa. Dra em Estudos Literários (UFG). Professora do Curso de Letras, da Universidade Estadual de Roraima. 


\section{INTRODUÇÃO}

Este breve artigo acadêmico tem como objetivo primordial analisar a construção de identidade cultural na obra de Nenê Macaggi e teve como norte a pesquisa científica realizada na Universidade Estadual de Roraima, a partir do projeto $O$ contador de histórias e o leitor de poesias ${ }^{3}$, e motivou para a continuidade no Mestrado em Letras da Universidade Federal de Roraima.

Ao escavar as entrelinhas dos romances $A$ mulher do garimpo, Dadá gemada, Exaltação ao verde e Nará-Sué-Uarená, percebe-se a construção de uma identidade cultural roraimense, a partir da ênfase na paisagem amazônica, no indígena, no mestiço, no imigrante, na culinária, nas indumentárias e até nos aspectos físicos dos personagens. $\mathrm{Na}$ verdade, a autora elabora "uma comunidade imaginada”, incitando o pertencimento HALL, 2006).

Com base nas teorias elencadas por Hall (2004), nota-se que Nenê Macaggi consiste em uma figura "traduzida", isto é, "produto de várias histórias e culturas interconectadas" (HALL, 2006, p. 52). Assim, ao imigrar para o extremo Norte, trouxe consigo traços da cultura paranaense, sotaque, tradições e histórias, mas, ao inserirse nesse novo contexto amazônico, começa a "negociar" com essa nova cultura. Esses "eu cruzados" parecem mais nítidos na personagem central do romance $A$ mulher do garimpo.

Com o olhar do neocolonizador, Nenê Macaggi recai no exotismo e fetichismo ao configurar a paisagem e o homem local. Em O local da cultura, Homi Bhabha (2004) aponta que o colonizador tende a descrever o colonizado como figura atrasada, exótica e as vezes até degenerada, como tentativa de justificação da conquista. Ao inserir-se na
Amazônia, Nenê Macaggi se comporta mais como etnógrafa que como romancista.

\section{O REGIONALISMO TARDIO EM NENÊ MACAGGI: A CONSTRUÇÃO DE UMA COMUNIDADE IMAGINADA}

A voz narrativa dos romances regionais de Nenê Macaggi destaca a riqueza da vegetação e de espécies de animais da região amazônica, a cultura de povos indígenas, a figura do mestiço e do imigrante, dentre outras temáticas. Sob esse prisma de literatura de expressão amazônica, os romances de Nenê Macaggi assentam-se em ambiguidades: de um lado exaltam o verde, os mitos, as belezas naturais da região, do outro retratam os conflitos sociais entre o indígena e os imigrantes, e ainda revelam as pragas, as doenças que permeiam a floresta amazônica. É nítido que os traços regionalistas marcam a obra macaggiana, o destaque: da culinária indígena, da exaltação da paisagem, da figura indígena e outros aspectos constroem um discurso identitário amazônico.

Ancorado em Stuart Hall (2004) em A identidade Cultural na pós-modernidade elucida-se que a representação de Roraima no discurso literário de Nenê Macaggi tem a intenção de instigar o sentimento de pertença do homem local ou mesmo busca a valorização por parte dos roraimados: sujeitos híbridos, como a própria autora paranaense.

$\mathrm{Na}$ busca de uma identidade nacional, no Romantismo, insurge uma dialética entre o localismo e o cosmopolitismo, isto é, a "tensão entre o dado local (que se apresenta como substância da expressão) e os moldes herdados da tradição europeia (que se apresentam como forma da expressão)" (CANDIDO, 1976, p. 113). Assim, o

3 Projeto coordenado pela Profa. Dra. Rosidelma Pereira Fraga, com apoio de bolsa de IC da UERR/CNPq. 
localismo teve como substância temática o índio e a natureza expressos nos moldes europeus.

Cumpre asseverar que o Arcadismo e, sobretudo o Romantismo foram as primeiras manifestações ufanistas, com ânsias do tipicamente brasileiro. Embora tenha culminado no pitoresco nacional, na idealização da natureza e do índio, tal manifestação "foi no Brasil um vigoroso esforço de formação nacional [haja vista ter sido a partir dele que se investiu] na construção de uma consciência literária nacional” (CANDIDO, 1976, p. 119). Nesta perspectiva, a etnografia fantasiosa do Romantismo (o ufanismo exacerbado e o destaque do índio cavalheiresco) aparece como tentativa de superação das inferioridades sentidas. É possível que isto resulte do fato do Brasil ter uma ambiguidade fundamental de "ser um povo latino, de herança europeia, mas etnicamente mestiço, situado no trópico, influenciado por culturas primitivas, ameríndias e africanas" (CANDIDO, 1976, p. 119).

O Modernismo, no entanto, reinterpreta essa característica brasileira: rompe com a figura do índio europeizado, subverte a natureza pretensiosa e ataca de modo implacável o academicismo. E, ainda, acentua a importância cultural de figuras recalcadas como: o negro, o mestiço, as populações rurais e o imigrante. Observe o fragmento:

O nosso Modernismo importa essencialmente, em sua fase heroica, na libertação de uma série de recalques históricos, sociais, étnicos, que são trazidos triunfalmente à tona da consciência literária. Este sentimento de triunfo, que assinala o fim da posição de inferioridade no diálogo secular com Portugal e já nem o leva mais em conta, define a originalidade própria do Modernismo na dialética do geral e do particular (CANDIDO, 2007, p. 119).

No entanto, cabe destacar que o Romantismo foi um movimento de suma importância, visto que o espírito revolucionário, a busca por uma "originalidade estética”, serviu de subsídio para outras épocas "e guarda similaridade com o espírito revolucionário modernista" (JOBIM, 2013, p. 207). Destarte, o Romantismo teria convergido para o espírito revoltado, inconformista, revolucionário do Modernismo.

Para José Luís Jobim (2013), o esforço de se construir uma identidade nacional parece ser mais uma tentativa de destacar os traços regionais, o que repercute na elaboração de uma literatura regionalista. Veja o que o referido autor pontua: "às vezes o que se buscou não foi o conjunto nacional, mas o de uma região" (p. 20). Para Candido (1976, p. 117), "o regionalismo, desde o início do nosso romance constitui uma das principais vias de autodefinição da consciência local...".

A rigor, percebe-se que a Dama das Letras buscou utilizar estratégias representacionais para elaborar em sua obra o senso comum de pertencimento. Hall (2006) elucida que há pelo menos cinco elementos que se podem acionar para se construir uma "comunidade imaginada", os quais são: narrativa da nação; ênfase nas origens; invenção da tradição; mito fundacional; e a ideia de um povo original.

A ideia de povo puro é percebida na obra A mulher do garimpo, em que o personagem Parente Alberto- Saldanha conta a numerosa quantidade de tribos indígenas $\mathrm{e} a$ miscigenação ao longo dos tempos. O contador de histórias diz:
(...) - houve perto de trinta mil índios no Vale do Rio Branco. Agora não há mais de quinze mil, poucos ainda puros, a maior parte já misturada a outras tribos, morando nas serras, nas matas e nos lavrados. Estavam acabando-se. Havia também muitos misturados aos brancos (MACAGGI, 2012, p. 149).

Já a invenção da tradição assume traços nítidos, sobretudo, através das lendas indígenas. Com receio das figuras lendárias, 
os índios de diferentes tribos seguem certos rituais, como: deixar fumo no mato para o caipora ou mascar tabaco para afugentar a mãe d'água. Veja-se o que o personagem Parente Alberto-Saldanha conta a José Otávio:

Os índios acreditam na mãe do campo, mãe da lua, mãe do mato, mãe do mato, e sua fauna de perseguidores e defensores é grande: o curupira dos lavrados, que amanso gado bravio e masca tabaco; a boiuna misteriosa; que aturde os caboclos com os esturros e os leva para o fundo do mar; o pai do mato, defensor da caça que o caçador que matar; [...]. mas o único que realmente existe, aquele que mais temem é o canaimé. (MACAGGI, 2012, p. 150).

A identidade cultural defendida na literatura de Macaggi, aproxima-se da concepção "essencialista ou ontológica”, em que a identidade nacional tem uma "essência que se reitera por tempo indeterminado" (JOBIM, 2013, p. 57). Com uma postura etnográfica, Nenê Macaggi revela romances que evidenciam a interpenetração de fatores sócio-históricos em sua literatura, como: a exploração da fauna e flora amazônica, o conflito entre fazendeiros e indígenas, a violência nos garimpos, a negligência política e outros entraves. De modo concomitante, a paisagem amazônica é exaltada por sua variedade de ecossistemas, bacias hidrográficas e pluralidade de povos.

Neste sentido, a produção romanesca de Nenê Macaggi, em especial $A$ mulher do garimpo: (1976); Dadá Gemada (1980); Exaltação ao verde (1984), Nará-Sué-Uarená (2012), parece construir um modelo identitário amazônico, a partir de "interseções culturais: migrações, hábitos, indumentárias, comida, denominações, ideias” (JOBIM, 2013, p.116). Tal elaboração é constatada, por exemplo, na obra Nará-Sué-Uarená, cuja narrativa apresenta o ritual da iapa, isto é, da incineração de cadáveres. No episódio em foco, a personagem central faz os preparativos para o cerimonial - esfrega nas pernas folhas de xiquibore2 para que fiquem fortes; coleta a lenha, e organiza os corpos dos que foram assassinados pela tribo inimiga:

\begin{abstract}
O ritual da iapa dos uiacás é parte de seus 'costumes religiosos' e eles comem o peicamuns aos poucos, nas refeições, pra ficarem fortes, corajosos e bons guerreiros, enquanto os napês [homem branco] jogam seus 'morridos' num buraco, dentro de uma caixa comprida toda enfeitada, fecham a tampa, cobrem com terra e os pobres ficam presos, taretares (podres) e cheios de 'bichins' (MACAGGI, 2012, p. 35).
\end{abstract}

$\mathrm{Na}$ cena do ritual fúnebre dos índios xamatautheres, os cadáveres são incinerados. Os ossos torrados são coletados, moídos e guardados. O peicamum (farinha de osso) é utilizado nas refeições para fornecer vigor físico. Esses hábitos são algumas das estratégias que a autora utiliza em uma construção discursiva sobre a identidade indígena. E a autora Teresa Maher (2006, p. 135), em Sendo índio em português, reforça essa assertiva ao destacar que "a construção da identidade não é de domínio exclusivo de língua alguma, ainda que seja, sempre da ordem do discurso".

Esses recursos simbólicos, são "teias de significados” expressas de diferentes formas: artesanato, linguagem, culinária, religião e outros (GEERTZ, 1989, p. 15). Trata-se, pois, de um conceito semiótico de cultura. A autora Minayo (2000) aponta que os símbolos envolvem o mundo material e simbólico, sendo recortes da realidade.

Não tão divergente, as comidas típicas das comunidades indígenas - a damorida, o chibé ou a bebida caxiri - também são consideradas herança cultural. No que tange aos bens materiais "podem ser classificados como bens de valor paisagístico, etnográfico, arqueológico, histórico, artístico ou de ofícios" (FERRARI, 2012, p. 122). O narrador da obra Nará-Sué-Uarená exalta o patrimônio paisagístico roraimense, o monte Roraima. Na cena o narrador convida o leitor a conhecer o referido patrimônio material: 
Por que não sobem e vão conhecer o Monte Roraima tão lindo, com aquele lago que, visto de avião, parece de fogo, soltando os filetes de água transparentes que formam o Auro diamantífero Contigo, o Mazzaroni, que desce para a Guiana e o terrível e gelado Arabopô, que entra na Venezuela (MACAGGI, 2012, p. 19).

No romance Exaltação ao verde (1984), da autora em questão, a personagem Luana acalentando a filha Imairari, embevece-se com a beleza da criança, que, apesar de ter sido fruto de um abuso sexual, quando nasce encanta a todos: uma mestiça moreninha, de olhos negros, de boquinha vermelha e sobrancelhas pestanudas. Neta de mestiço e bisneta de índio. $\mathrm{O}$ nome indígena que recebera significa o nome de uma serra que adorna a vila do Surumu. Convoca-se o leitor para examinar o que Luana diz no ímpeto de ternura:

Quer dizer que minha florzinha branca de seringueira é bem brasileira, hem? E roraimense, pois o nosso Paraíso fica no Rio Branco.

$\mathrm{Eu}$ lhe falo assim, filhinha, porque no futuro, mesmo que venha a ser até uma doutora, não se envergonhe de ser mestiça, ouviu, coisa rica da mamãe? Porque índio também é gente e nossa história conta muitos episódios de índios que foram heróis, como Arariboia, Tibiriçá e outros (MACAGGI, 1984, p. 290).

A cena mostra outro exemplo de desrecalque localista na obra de Nenê Macaggi: a exaltação da figura mestiça Imairari. Não somente dotada de delicada beleza, mas com potencial para ser até doutora e, mais que isso, posta na história com audacioso protagonismo (pois "índio também é gente”), superando a imagem estigmatizada de mera coadjuvante.

Cabe destacar o episódio, da obra Dadá gemada doçura, em que o personagem Arnaldo sacia a fome da saudade que sentira da culinária amazônica, ao retornar para o já território federal de Roraima:

Com muito apetite um bom pedaço de ventrecha de picarucu assado com chibé de farinha d’água. E ao ver ali na sua frente aquele chibé alourado enfeitando o seu prato, lembrou-se de quantas vezes, pelo mundo vasio (SIC) [vazio] em que vivera, sentira saudade daquela comida típica de sua terra (MACAGGI, 1980, p. 177).

$\mathrm{O}$ conceito de identidade cultural sociológica difere da concepção pósmoderna. Naquele, o sujeito está ligado a um espaço geográfico particular, a raízes culturais vistas como patrimônio imaterial e material. No Norte, os vaqueiros nordestinos analfabetos, com sua imensa prole, sujeitamse aos patrões. Na verdade:

\begin{abstract}
O fazendeiro pouco ajuda ao vaqueiro com remédio e roupas e o pobre só tem mesmo de graça, a carne, o leite e uma casa, quase sempre ruim de taipa. [...] Os filhos nascem e morrem analfabetos, porque não há escola isolada. E como há crianças no interior (MACAGGI, 2012, p. 99).
\end{abstract}

Deste modo, mesmo na terra da promissão, o vaqueiro tem uma vida subalterna, passa necessidades financeiras e está sob o "cabresto" das autoridades, governo "que só olha para o Rio Branco [Roraima] quando precisa dos nossos votos..." (MACAGGI, 2012, p. 99). O episódio pode ser associado à cena de Canaã, terra que manava leite e mel, presente na obra A bagaceira, de José Américo de Almeida, a qual faz intertexto bíblico, mas no sentido de que os sertanejos, trabalhadores de engenhos, viviam em terras prósperas, mas morriam de fome como em Canaã. Para dar pertinência ao que se afirma, convida-se o leitor a conferir a voz narrativa do aludido romance quando diz "há uma miséria maior do que morrer de fome no deserto: é não ter o que comer na terra de Canaã” (ALMEIDA, 1972, p. 3).

Já na obra Dadá gemada doçura e amargura, a voz narrativa apresenta as fazendas, na perspectiva não mais dos vaqueiros, mas dos fazendeiros. Como pode ser observado na cena em que Alfredo ao visitar a fazenda "Alvorada” diz: “- que lugar soberbo! Que capim, que gado luzido, 
que águas! Dá gosto de viver aqui!” (MACAGGI, 1980, p. 85). Em outra passagem, Naldo-Macuxi irrita-se com a degradação da Amazônia e adverte:

[...] na nuvem Branca e na Alvorada não se mata mais caça e quanto a pescar ... só com anzol ou rede pequena. Porque não é preciso matar animais. Graças a Deus aqui ninguém passa fome nem passará, pois temos muito porco, carneiro, gado e galinha para abater (idem, p. 202).

Eufórico com o retorno a Roraima, o personagem sente-se indignado com a degradação das espécies amazônicas. E deixa claro a fartura nas duas fazendas, o que não justificaria o vaqueiro caçar, pescar em grandes quantidades e pegar ovos de tracajás em épocas de desova.

A poética de Nenê Macaggi, é construída a partir de um discurso identitário que exalta a beleza indígena e mestiça, como a formosura da índia Nara-Sué-Uarená. Em Exaltação ao verde: terra, água e pesca, a beleza mestiça é evidenciada, com as personagens Luana e Carla:

Luana, moreno-claro, pele acetinada, olhos
negros, resgados e pestanudos como os do
pai, boca rosada, cabelo castanho e comprido,
usado em tranças ou caído nos ombros. Era
alta esbelta, um mimo, enfim!
Carla era a mais baixa e rechonchuda, com
olhos verdes e brilhantes como os da mãe,
bons dentes, boca rasgada e carnuda e corada,
como uma atã do Alto-Cotingo, no extremo
norte do Território, nascido no monte
Roraima. [...] E muito bem educadas para o
meio rude em que viviam. (MACAGGI,
1984, p. 152).

O fragmento acima citado reforça, ainda, a hipótese de um regionalismo tardio, como já foi discutido no capítulo anterior. Segundo Candido (1976) a ênfase de figuras recalcadas como o imigrante e o mestiço são marcas do Modernismo brasileiro, sobretudo do viés regionalista.

Diante do exposto, fica patente a importância de se ler, analisar, refletir e fazer diálogos entre a prosa regionalista de Nenê Macaggi e o Romance de 30, pois são obras que constroem modelos de identidades culturais, além de ser nítida a interpenetração de fatores históricos e sociais na tessitura. Assim, os romances efetuam denúncias sociais como o descaso das autoridades com os retirantes, com os pobres miseráveis que definhavam de fome no Nordeste. No Norte, a exploração e descaso continuam com as figuras de alguns fazendeiros e pessoas políticas.

\section{CONSIDERAÇÕES FINAIS}

Paulatinamente à análise sobre a prosa regionalista de Nenê Macaggi, torna-se possível inferir sobre a presença de um regionalismo tardio no extremo norte do país. Isso ficou evidente a partir de uma análise estética dos romances macaggianos. Tal procedimento alicerçou-se na teoria de desrecalque e na dialética entre o localismo e o cosmopolitismo, ambas defendidas por Candido (1976); e, ainda, na ideia de construção de uma "comunidade imaginada”, proposta por Hall (2006).

A princípio mostrou-se a importância das obras regionalistas de Nenê Macaggi para a construção de um modelo de identidade dita roraimense. De antemão, deixou-se claro que se tratava uma identidade construída discursivamente, a partir de teias de significados culturais (GEERTZ, 1989).

A ênfase atribuída aos patrimônios materiais e imateriais parece ser por parte da Dama das Letras uma tentativa de particularização da cultura do extremo norte frente às demais regiões do Brasil, embora se admita que a identidade roraimense é construída a partir "híbridos culturais" (HALL, 2006). Assim, em seu processo de formação, o Estado de Roraima sofre influxos culturais de imigrantes de várias partes do país, sobretudo, advindos da cultura nordestina.

Nessa perspectiva, o sentimento de pertencimento roraimense é invocado a partir da descrição da beleza verde da flora 
amazônica, da exuberância do Monte Roraima, da Serra do Tepequém, da riqueza de espécies da fauna, como também penetrando nos problemas sociais, como a degradação da flora e fauna amazônica, e brigas entre fazendeiros e indígenas ou dentre outras problemáticas desveladas.

Na obra macaggiana, o discurso identitário é construído, ainda, a partir do destaque de aspectos físicos, como a formosura das jovens indígenas, a exemplo a personagem Nará-Sué-Uarená. A beleza mestiça, também, é evidenciada, através de figuras fictícias como Laura e Carla, da obra Exaltação ao verde. A voz narrativa coloca à margem a beleza eurocêntrica da mulher de bochecha rosada, de cabelos loiros e olhos azuis e exalta a formosura da índia e mestiça de olhos negros e "puxados", boca carnuda e pele acetinada. Portanto, são elaboradas representações culturais, Nenê Macaggi constrói representações simbólicas do sujeito roraimense (indígena ou mestiço) através de figuras fictícias que apresentam fortes traços nortistas.

\section{REFERÊNCIAS}

CANDIDO, A. Literatura e sociedade:

estudos de teoria e história literária. 5. Ed. revista. São Paulo: Nacional, 1975.

GEERTZ, Clifford. A interpretação das

culturas. Rio de Janeiro: Afiliada, 1989.

HALL, S. A identidade cultural da pósmodernidade. Rio de Janeiro: DP e A, 2006.

MACAGGI, Nenê. A mulher do garimpo: romance do extremo sertão do Amazonas. $2^{\mathrm{a}}$ ed. Boa Vista: Gráfica Real, 2012. . Dadá- Gemada, doçura e

amargura: o romance do fazendeiro roraimense. Boa Vista: Gráfica Real, 1980. . Exaltação ao verde: terra, água: o romance do Baixo-Rio branco. Boa Vista: Gráfica Real, 1984.
Boa Vista: Gráfica Real, 2012.

WANKLER, Cátia Monteiro. Portas, janelas e molduras: topofilia, identidade, globalização e os estudos de literatura de Roraima. XIII Congresso Internacional da ABRALIC Internacionalização do Regional. Campina Grande: UEPB, 2013.

\section{AGRADECIMENTOS}

Agradecemos ao apoio do órgão de fomento CNPq, pela bolsa de pesquisa e a Universidade Estadual de Roraima que possibilitaram a iniciação científica no curso de Letras, campus de Rorainópolis, servindo de grande motivação para continuidade na pesquisa Stricto Sensu, com ingresso no Mestrado em Letras, na Universidade Federal de Roraima.

romance dos xamatautheres do Parima.
} 